\title{
LAS PRERROGATTVAS PARLAMENTARIAS EN LA DOCTRINA CONSTITUCIONAL ESPAÑOLA
}

\section{Francisco Femández Segado}

Cafedrático de Derecbo Constituctonat en la Universidad de Santiago de Compostela.

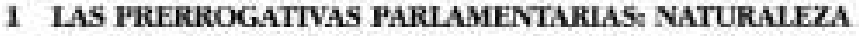 Y FUNCION}

1 Un sector amplio de la doctrina hat atisbado en el parlamentarismo medieval inglés los primeros antecedentes de lo que boy conocemas cocno prerrogativas parlanentarias, $y$, de modo muy significado, de las das más caracteristicas: la inviolabilidad (freedom of speecb) y la immunidad (freedom from arrest or malestation), bien que no falten autcres que, como Fernindez-Miranda, consideran irrelevante la freexlom from ansit coeno ofipen de la inmunidad pariamentaria, por cuanto se trataria de una instatución derivada de la curia medieval, generalizada en gran parte de Europa, y que nuacia dexo de responder a su fundamento originarlo, esto es, a la exigencia de seguridiad en un peligroso $y$, can frocuencia, largo vicje para acudir a las llamadas del rey a "Consejo". Por lo mikmo, el crigen de la moderna inmunidad había que verlo en la Franciar revolucionaria.

Al margen ya de esta polémica, lo ciento es qque el triunto del Partamena en la Revolución Gloriasa, en su histárico conflicto con el rey, conducinán a la definiriva corragracićn de estas prerogativas, muy especiaimente de ta inviolabsilidad, prentogativas que, can mayur rigor historico, bien podemos tildar, en aquel 
monento histórico, de aunénticos powilegios, Y acl, la declaración DX del Bill of Rigais contemplarí el privilegio de la inviolabiliklad en estos terminos: las lifbertades de expresión, descusión y actuación en el Parlamento no pueden ser puzgadas ri investiggadas poe olru tribunal que el Parlamento', Por su parte, la freediom from arest, cuya finalidad sustancial, en aquel contexto histórico, era dejar sin efecto kos mandatos de arresto expedidos contra un parlamentario en virtud de procesas che naturaleza civif ${ }^{1}{ }_{2} 2$, caeria en desuso, tiempo desputs, al ser abolida la prision por deudas.

La Revolución francesa incorporarí a su instrumerLal juridico, desde sus primeros monentos, el instituto de la inviolabilislad, bien que concebido con ura extraordinarha amplitud, como revela el decreto de 20 de junio de 1789 , de la Asamblea Nacional en que se habia autoconstituido ef Teroer Eistado, nomma que se abre presctibiendo de modo rotundo que: "La Asamblea prodama que ha persona de cada digatado es inviolable," In decreto de 26 de junio de 1790 perfeccionars el sistena. La inviolabilidad reclarrada por el Parlamento para sus miembros no perseguia en oltimo término, como senalana con ackerto Barthelemy $y^{3}$, s. $^{-}$ bo trasferir a las astmbleas representiaisas del liberalismo una parte de las beneficios def viejo axicoma abschutista: The king can not do wrong." La propia terminología empleada en un principio por los revolucionarios parece apuntar en este sentìlo.

1 FHNG

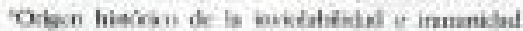

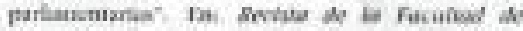

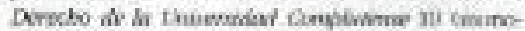

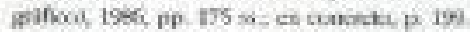

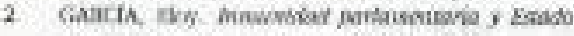

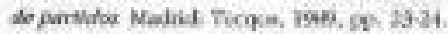

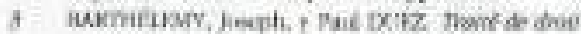

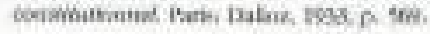

II 22 de marro de 1791 se delimiraba con cierta nitidez el instiluto od la inmunidad, al significarse que ésta no entrañaba una traslación de competencia jurisdiccional, sino la necesidad de la autcorización de la Asamblea para procesar a uno de sus miembros. $Y$ la Canstitución de 3 de setiembre de 1791 perfilara claramente la inviolabilidad y la immunidad. Su articulo 7 de la sección quinta del capinulo 1 del tîtulo 111, regularí la inviolabilidad en estos Iérminos: "Les repuesentants de la nation scont inviclables: ils ne pourront étre recherchés, accusés ni jugés en aucun ternps pour ce quils auront dit, écrit ou fait dans lexescise de leurs fonctions de reprisentants:" $Y$ ef precepto inmediatamente sigueiente delineará la inmunidad como sigue: Tls llos representantes de la nación] poument, pour faits crimincls, étre saiais en flagrant délit, ou en vertu d'un mandat d'amét; mais il en sera donné avis, sans delai, au Corps legislacif sura decide quit y a tieu A accusation,"

Nuestra Constirución de Cadiz acogeria el instiluto de la inviolabilidad, sicndo el ódiligo constitucional de 1837 el primero que distinguiria entre inviolabilidad $e$ inmuniclad, diferenciación que sería recibjda pot los sucesivos textos constitucionales del pasado $y$ del actual siglo, hasta Dlegar a nuestra vigente Constirución de 1978 que, coxtro es sobradiamente canocido, acoge las prernogativas parlamentrias en su articulo 71 , de conformidad con el cual:

7. Los dipusaklos y senadores goasarin de inviolabilidad pos las opininnes manifes. tadas en el ejercicio de sus funciones."

-2. Durante ef periodo de sa maniluro los diputados y semadores gocardn 2 simismo de iniminidad $y$ soblo podidn ser detcaicbs en caso de flagrane telito No podrán ser taculpados is processidos $\sin$ la previa uunorizacios de la Cifrnara respectiva." 
3. En las causas contra dipatados y sentadores sera coaperent la sala de lo Penal del Tribunal Suprenso."

4. Los diputadias y sensdores percibiran una asignación que seri fijada por las respectivas Caimuras."

2. En el marco de un Estudo social y democrático de Derecho que acoge como valores superiores de su ordenamiento jurid: $\infty$ (art. 1,1 de la Constitución espanola -CE-), entre ctros, el valor justicia $y$ el valor igualdad, es de todo punto innece. sario advertir que la naturaleza y función de las prernogetivas partamentarias ya no pueden seguir siendo aquellas con las que naxieron. Es decir, ya no estamos ante privilegios personales, pues es unat obviedad bincompatibilidad de los mismos con squel Fistado

En esta misma dirección, el joez de la Canstitucion ${ }^{4}$ ha puesto de relieve que la inmunidad parlamentaria no puede concebirse como un privilegio personal, esto es, como un instrumento que únicamente se establece en beneficio de las personals de los diputidos o senadores, al objeto de sustrier sus conductis del conocimiento o decisión de jueces o trithunales. Ia existencia de tal tipo de privilegias pugnaria, entre otras cosas, con los valones de "justicia" e "igualdad" que el articula 1.1 de la CE reconoce como 'superiores' de nuestro ordenamiento juridico. La inmunidad -anade el Alto Tribunal-, como el resto de las prenogativas que el articulo 71 de $1 \mathrm{a}$ mismu Constituciồn establece, se justifica en atención al conjunto de funciones parlamentarias, respecto a las que tiene camo firalidad primordial su probección.

fin otro momento', el Alto Tribunal, insistiendo en ba misma linea-tras recordar

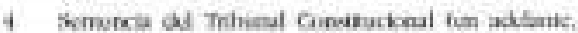

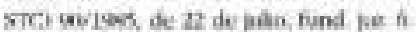

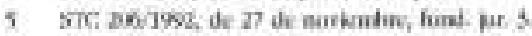

que. "siempre ha habido acuerdo en que la inmunxlad, al igual que ctras premogativas parlanentarizs, peto con mils razón ésa, no es un privilegio, es decir, un derecho particular de determinados chudadanos que se vieran, asi, Eavorecidos respecto del resto de los mismos"-, se decanta nitidamente en favor del canictor objurivo de las prerrogatives partamentariss, carácter que, en el caso de la imnunidad, se refuerza de tal modo que la misma adquiere el senticho de una premogatiea instirencional

La inviolabilidad e inmunidad parlamentarias, aunque tienen distinto conteni. do objetivo y una finalidad especifica, encuentran su fundamento en el objetiwo comun de garantizar la libertad e indiependencia de la institución parlamentaria, $y$ en tall sentido son complementarias $s^{6} . \mathrm{Al}$ servicio de este objetivo se confieren estos privtlegios, no como derechos personales, sino como derechos reflejos de los que goxis el parlamentario en su condición de miembro de la institucion y que solo se fustifcan -pocs todo privilegio requiere fustificacich- en cuanto que tal privilegio es condición de posibilidad del funcionamiento eficaz y libre de la institución?, en tona siterprevación estricta o restrictas, tanto en el sentido lógico de sujeción a los limstes objetivos que jes imponie la Constitución, como en el teleobógico de razonable proporcionalidad al fin al que responden, debiendo rechazarse, en consecuencia, todo criterio hermenéutico permisivo de una utilización injustificada de los poivikegios, que conduzca a un resultado de ptivacion, constitucionalmente alicita, de la via procesal pertinente prevista en la ley.

En sintonia con esta interpretación es tricta de las prertogativas que nos ocupan,

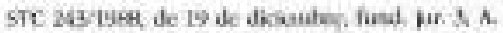

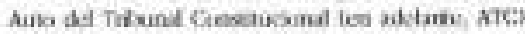

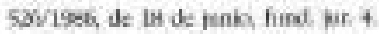


el "interprete supremo de la Constitución" ha rechazado la introducción de la via analógica como criterio hermeneutico en relación con estos institutcos. Fillo casa is la perfección con el lugar privilegiado que en la econormia general de nuestra Constitucion ocupan los derechos fundamentales y libertades piblicas que en ella se consagran. De ello resulta no sólo la inconstitacionalidad de todos axpuellos actos del poder-cualquiera que sea su naturaleza y rango- que los lesionen, sino tambiêtn, como ha significads of Alto Tribunal ${ }^{y}$, ta ne. cesidad de interpsetar la ley en la forma más favocable a la maximización del contenido de aquellos derechos y libertades.

Clertamente, los derechos y libertades no son absolutos, como una reiteradisima jurisponidencia ha puesto de relieve, pero. si ello es asi, menos aũn puede atribuarse dicho carícter a loo límites a que ha de Someterse el ejercicio de tales derechas. Cuino una vez más afirma el Tribunal ${ }^{10}$, tanto las "normas de libertad" como las llamadas "normas timizadoras" se integran en un único ordenamiento inspirado por las mismos principias, en el que, en viltimo térmiDa, resulra ficticta la contraposición entre el interes particular subyacente a las primeras y el interés publico que, en ciertos supuestos, aconceja su restricción. Se produce, pues, un régimen de concurrencia normativa, que no de exclusión.

Esta concurrencta de nomas deviene, en úlrimo témmino, de çae tanto los derechos individuales como sus línites, en cuanto estos derivin del respecto a la ky y a los derechos de kas demils, son igeatmente consideridos par el irticulo 10,1 de 4 CE camo "fundamento del onden polits-

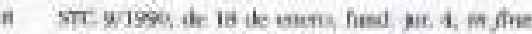

y $5 \pi \mathrm{r}$ 6h/sks de 23 de mark find has. 2

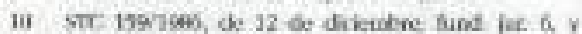

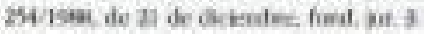

cri $y$ de la par sxcial". La concurrencial entre las "nomas de libertad" y las "normas limitadoras" entranta que unas $\mathrm{y}$ coras operen con el mismo grado de vinculatoriedad $y$ actien reciprocamente. Como sesultado de esta intericción, la fuerza expansiva de todo derecho fundamental restringe al alcance de las normas que establecen limines al ejercicio de un derecho, de ahí la exigencia, relteradisiana por el $\mathrm{Al}$ to Tribunal, de que los limites de los derechos fundarmentales hayan de ser interpretados con criterios restrictivos y en el scmticlo mils favorable a la eficacia y a la esencia de tates derechos. Y de ahí precisamente la doctrina coxstitucional que rechaza una interpretación expansiva de las premogativas parlamentarias a fin de que no devengan en privilegios que puedan lesionar derechos fundkmenuales de terceros.

Las pautos interpretativas expuesas se hacen más nectesarias, si aún cabe, si atendemos a la praxis de estas institucianes y -mauy significativamente- del instituto de la intuunidad, pues en tal caso la conclusión que bemos de entreacicar es del todo pesimista. Cono apuntara Fernández-Miran$\mathrm{da}^{11}$, la utilizacón de la prerrogativa de la inmunidad por los Parlamentos, la generosidad y la arbitntriedad con que han denegado sisternaticamente la mayoria de los suplicatorios, la han corvertido en un abténtico privilegio personal que ademais es incapaż de cumplir siquien las funciones constitucionales que le servian de funclamento. En idéntica dirccoión. FernandezVagas ${ }^{12}$ reconoce ba existencia de unos re-

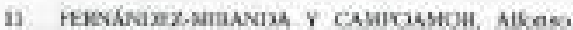

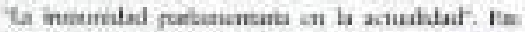

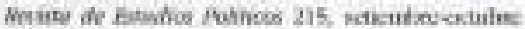
19ק7, m. art ss in comsests D. 235

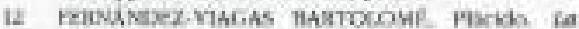

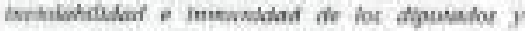

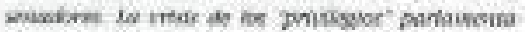

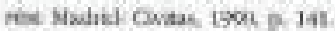


flejos corporations de los parlamentarios, tendentes a crear mecanisanos de attodefertsil que parecent enconitar su mejor expresión en una institución tan eficaz -en has inicius de la democracia- couno be de ba inmunidad. En último término, camo bien actvicrte Eloy Garcia ${ }^{13}$, las abusos y comuptelas, aun siendo crusa efectiva de ba degradacion en que actualmente se encuentra sunida la instituciōn, resultan insuficientes para explicar las verdaderas manose de una crisis que, mis que de la inmunidad misma, lo es de los presupuestas constitucianales que un dia le sirvieron de base y que un tiempo -que estaria par verse si ya es pasido-justificaron su existencia.

Una última reflexion es preciso hacer. De la naturaleza objetiva de las prerrogativas parlamentarias se deriva su frrenunciabilidad por las parlamentarios. Dicho de cro modo, las premogativas no son disponibles por aquelloxi, de manera que una eventual renuncie a las mismas careceria de toda eficacia juridica, pues es evidente que en cuanto excepciones al derecho común que son, tales prerrogativas les cor. responden en canexión con las funciones pablicas que desarmollan. En idéntica dirección, lace ya más de medio siglo Barthé:Lemy y Duez sostendrian, refiriéndose a las prerrogativas que nos ocupan- "Elles en sont pas donnes aux parlimentaires dans leur propre interet, mais dans l'interet du libre exereise de la fonction: ils en peuvent done $y$ nenoncer ${ }^{-14}$, Y entre noscotros, recientemente Abellinn 15 recuerda, refiriéndose a la inmunidad, que el diálogo sobre

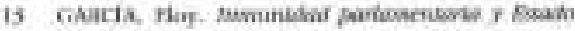

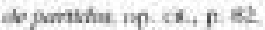

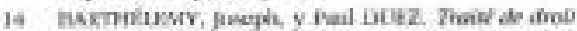

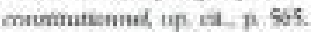

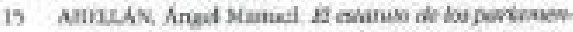

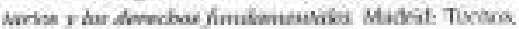
lowh $\mathrm{P}, \mathrm{re}$ la garantia se produce exclusivamente entre el organo juzgador y la Camara, y el interes de hacer valer la prerrogativa se concecle a ésta y no al parlamentario.

No podemos finaliear estas reflexiones gencrales previas sin poner de relieve la notabilisima aportación que el Tribunal Constitucional ha becho con vistas a ha racionslización de unas instituciones que, como bien se ha dicho ${ }^{76}$, por su anacronismo y su bissoria encajin difficilanente en los principios propugnados por nucstra Constitución.

\section{IA INVIOLARTIDAD PARI.AMENTARIA}

\subsection{Concoporo $y$ delimulación material $y$ finctoral}

1. Ia inviolabilidad reconocida por el arlicula 71.1 de nuestra Constitución puede ser conceptuada como aquetla prerogativa de que pozarán los senadores y diputados respecto de las "opiniones manifestadas en el ejercicio de sus funciones", lo que, a juício del "intérpete supremo de la Constitucion"17, supone que no pueden ser sometidos a procedimiento alguno tanto por las referidas opiniones camo pxr los wotos que emikan en el seno de la Cámara de que forman parte.

Comso fficlimente se percibe, la primera problemática que plantea esta premogativa es la de hasta dónde aleanza el cjercocio de

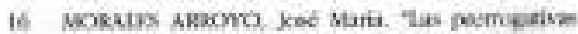

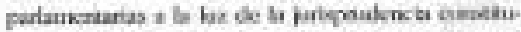

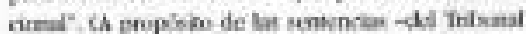

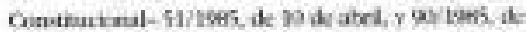

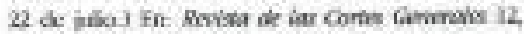

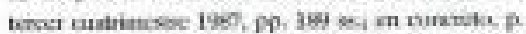
$2 \mathrm{t}$.

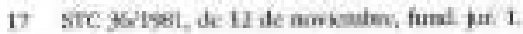


las funcianes de un parlamernario: se circunscribe el mismo a la actividad oficial o, por el contrario, puede el representante parlamentario ejercitar la función que le ha sido conferida por cuilquier cance abierto a los demis ciudadanos, sin perder por ello su función el curácter que le comes. ponda, por razón de la materia y objeto de la actividad, continuando, por ende, cubjerto por la inviolabilidact?

Es claro -corno ha reconocido el Tribunal Constitucional ${ }^{1 R}$ - que la inviolabalidad parlamentaria se orienta a la preservación de un âmbito cualificado de libertad en li critica y en la decisión, sin el cual el ejercicio de las funciones parlamentanias podría resultar mediatizado, y frustrado - por elloel proceso de libre formaciôn de voluntad del órganolis.

2. Esta garantia de diputados $y$ senadores requiere, por lo mismo, de una delimitación material y funckonal. Respecto de la pritnera, cree el Tribunal' ${ }^{20}$ que la garantia no ampara cualesquiera actuaciones de fos parlamentarios y sí solo sus declaraciones de juicio o de voluntad, que es to que debe entenderse por el termino "opiniones" a que alude el articulo 71.1 de ta $\mathrm{CE}$

Mas problemática se presenta la concteeión funcional del ámbito de la prenogativa, que puede presentar, de principio, algunas dudas, $y$ en especial la relativa is si la inviolabilidad cubre roda la actuación de "relevancia politica" del parlamentario o sl, núls estrictanente, la proterción dispensa. da por esta garantía no alcanza sinco a la

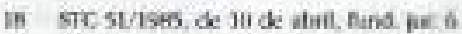

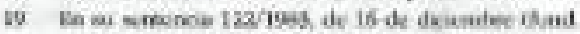

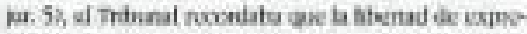

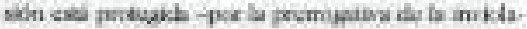

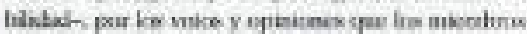

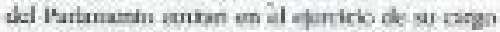

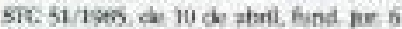

conchxta de su titular en tanto que miemboo dei ôrgano colegiado, cesando, por Jo tanto, cuando el sujeto desplegase yz su conducta -inchuso aquella que tuviere "trascendencia politica"- al margen de las funciones parlarnentarias.

La doctrina espatiola se inclina casi úntcamente por la comprensión mấs estricta de esta premogativa, posición dominante asimisuo en la liseratura jurldica extranjerz. $\mathrm{Y}$ asi, entre nosotros, se ha entendi$\mathrm{do}^{21}$ que la actuación del parlamentario, en el ejercicio regular de sus funciones, para la formación de la voluntad de lax cosmsera, debe inscribirse en el procedimiento constikucional $\gamma$ reglamentariamente esta blecida. Ello entrana que aunque nuestra Constitución, a diferencia de ceros códigos politicos (crovo el alemin o el griego), no establece expresamente ninguna limitación, es evidertte que la inviolabilidad estíl sujela a ímites. En clla, por ejemplo, no pueden enccotrar amparo ni las calumnias, ni las injurias, ni conceptos ofensivas contra personas o instituciones, ni la apología para la counisión de delitos, pues tales manifestaciones mal pueden contribuir al ejercicio de las funciones parlamentarias $^{22}$

A fin de intentar delimitar funcionalmente el almbito que cubre este instituto, el juez de la Constitución ba acudide ${ }^{23}$, en primer término, a una interpretación literal y sistemalticia del codenamicnto constaucional, y inás tarde, a vena interpretación fira. listo.

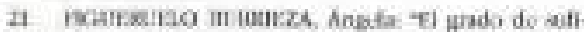

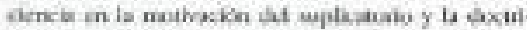

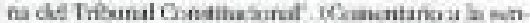

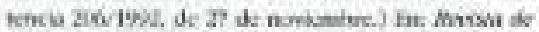

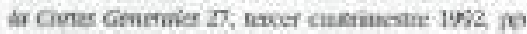

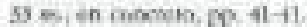

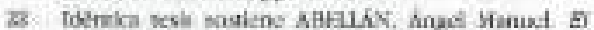

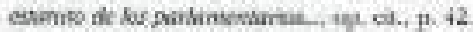

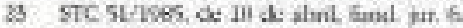


El nexp entre inviolabilidad y cjercicio de funciones propias a la condición de parlamentario estś cliramence expuesto por el proplo artículo 71.1 de la CX. A no ser que bl expresión "funciunes" que recoge la chada norasa se entendiera en un sentido inespectilico sde corte socioloblico y no jurídicol, las mismas debieran identifi. earse en las que son propeas det diputado o senador en tinto que sujetos portadores del ćrgano partamersiafio, cuya autonombs, en definitiva, es la protegicha por esta garantia individual. Por lo mismo, el diputado a senador sjerserd sus funciones solo en la medicla en que participe en actos parlamemarios y en el seno de cualesquiera de las aticulaciones argínicas de las Contes Cenerales. El articulo 21 del heglamento de la Alta Cámara corroboca de modo inequivicco esta interpretación al atribuir a las semadores et goce de esta premogativa de $\mathrm{L}$ inviolabilidad "por las opiniones manifiestadas en actos parlamentarios y por los votos emitidos en el ejescicio de su cargo",

En apoyo de lit interpesación adocida puede atenderse asimisma a la determinación del arrículo 67.3 de la Constitución, a cuyo tencr: "las reuniones de parlamentrios que se celebren sin corvocattoria reglamentaria no vioxularín a has Camaras, y no podrín ejercer sus funciones ni coten. tar sus privilegias." El Tribumal Constitucioaul considera patente que el sentido de es. te precepto es ef de vincualar el reconocimiento de la que llama "privilegios" parlamentarios al funcionamiento regular de las asambleas y de sus ónganos. Refuerza esta tesis el hecho de que la inviodabilidad por las opiniones vertidis se vea necesariamente contrapesada por la sujeción a la disciplina parlamentaria.

Si el examen literal y sistematico de las proceptos canstitucionales y reglamentarios nos conduce a esa comprensián estrica de 1a irviolabilidad, otro tanto acontece con una interpretación finalista de caa garantía.

Como ya tuvimos aportunidad de senalar con anterioridad, las prersogutivas purlamentarias han de ser interpretadas estrictamente para no devenir privilegios que puedan lesionar derechos fundamentales de terceros. Til entendimiento estrikto debe hacerse a pantir de una compensión del seritide de la prenrogativa y de la finalidad a que ésta responde. Desde este enfoque, como la doctrina ha puesto de relieve, en roflexión que bace propia el juez de la Constinación, las prerrogativas parlamentarias son "sustmccionx's al derecho comin conectidas a una funcion: y solo en tanto esta función juridica se ejerza pueden considerarse vipentes. Ello quiere decir que la garantía serai legitima en ta medida en que sa estructura la hagat adecuada a sa objetivo, sin que en ningün caso pueda ser dessirtuada para convertirla en origen de privilegio

Pues bien, en cuanto que la inviolabildad responde al espectico interés de proteger la labre discusión y decisićn parlamentarias ${ }^{24}$, decayendo tal protección cuando los actos hayan sido realizados por su autoc en calidad de ciudadano (de "politico", incluso), fuera del ejercicio de competencias y funcianes que le pudieran coresponder como parlamentario, es claro que las funciones relevantes a los efectos del articulo 71.1 de nuestra borma suprema no son indeferenciadamerate todas las realizadas por quien sea parlamentario, sino aquellas imputables a quien, sićndolo, actúa jutidicamente como tal.

E1 "guardiain de ta Constitución"25 entiende que, eon carácter general, esta debe

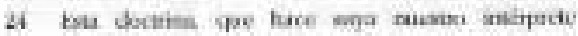

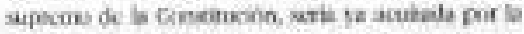

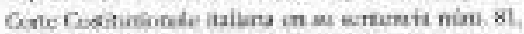
de 27 or anmo de 145

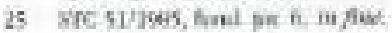


ser la interpretación del ámbito funcional en que se proyecta la garantia de la imvio. labilithad. Un entendimiento estricto que, en cualquier caso, no impide las necesarias matizaciones, pudiendo incluso llegar a admitirse que ha prerrogativa puede amparar, también, los actos "exteriores" a ta vida de las Cámaras, que no sean sino reproducción literal de un acto parlamentario.

La interpretación expuesta no debe en modo alguno conducir a entender, como hacia el demandante en el proceso cerrado por la sentencia 51/1965, que la reglamensación de las Cimaras pone limites a la actividad páblica de los parlamentarios, pues tal normación se dircunscribe a precisar cuáles de sus actividades constituyen sus funciones, pudiendo, al margen de ellas, camo resulta obvio, tormular los parkmentarios las criticas a la acción del Gobierno que tengan por converviente, combo cualcguier ciudactano, peto sin gocar de la protección del articulo 71.1 de $\mathrm{L}$ CE, sino solka de la genérica libertad que reconoce el articulo 20 de la propia norma suprema.

Digamos, por viltimo, que esta garantía de los parlamentarios no decae por la extinción del mandato, como precisan el artículo 10 del Reglamento del Congreso y el artículo 21 de la norma reglamentaria del Senado, preceptos ambos que disponen que el soce de esta premogativa por parte de diputados y senadores se producira "aun después de haber cesado en su mandato".

En suma, a la vista de la doctrina constitucional expoesta, podernos conceptuar la invicolabelidad parlamentaria couno un privilegio de naturaleza sustantiva que garantiza la irresponsabilidad juridica de los parlamentarios por las opiniomes manifescadas en el ejercicio de sus funciones, en tendiendo por tales apuellas que realicen en actos parlamentarios $\bar{y} \mathrm{cn}$ el seno de cualquiera de las articulaciones de las Cor- tes Generales 0, por excepción, en actos extericores a la vida de las Cimaras que sean reproduccicn literal de un acto parlamentario, siendo finalidad especifica del privilegio asegurar a través de la libertad de expresión de los parlamentarios la libre formación de la voluntad del árgano legis. lativo al que pertenezcan ${ }^{25}$.

\subsection{Natumaleza uuridico-penal de la inviolabilidad}

El Tribunal Constitucional no ha entrado a pronunciarse sobre la controvertida naturaleza, en el imbito penal, de esta prerrogativa, limitindose a recordar ${ }^{77}$ que mientras para unos es causa de inimputabilidad, para otros ha de ser considerada como una eximente de antifjuricidad. Psta falta de pronunciamienco jurisprudencial no obsta para que no nos hagamos eco, siquiera sea de moda sumario, de las diferentes posturas doctrinales al efecto.

Como bien adviente Pizzonusso ${ }^{25}$, las inmunidades parlamentarias (genérica expresión con la que alude a las que nosotras llamamos prenrogatizas parlamentarias) se detikan de exigencias conectadas con la especilica foma de gobierno vigente en un pals, $y$, en consecuencia, se insertan en ta teoria del derecho constitucional; sin enbargo, aquellas deben examinarse, por lo que concieme a sa estructura técni$\mathrm{c}$, desde el punto de vista del derecho penal (la inviolabilidad) y del derecho procesal penal (a inmunidad), a cuyos sistemas pertenecen.

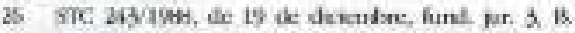
Dectina twa reisenda en la 5202067902 , de 27 de coviauton fund in: 5

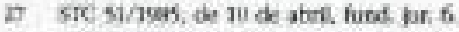

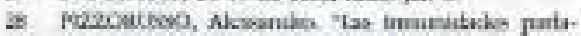

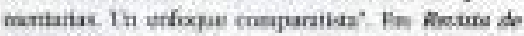

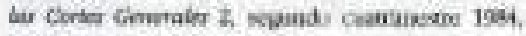

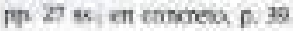


El propio Piczonusso ${ }^{29}$ ha enumerado has que el entiende como tres categorizaciones juridico-permales clel instituto: causal personal de exiención de la pena, causa de justificación y causa de exención de la punibilälad, para llegar, en úximo úrmino, a la conclusión de que resulta dificil tomar partido por alguna de las anteriores opiniones doctrinales, ya que en realidad el debate pone de manifiesto factores indudablemente contradictarios que son propios del instituto examinado, y que un examen del mismo desde el punto de vista del derecho constituclonal contribuye a poner de relieve.

En Espana, micotras Quintano Ripollés considera la inviolabilidad como una causa absolutaria -lo que entrañs mantener la antijuricidad de la acción, excluyendo su punibilidad ${ }^{30}$-, Rodriguez Devess sostiene que la inviobabilidad es una causa de justificación, por cuanto es un derecho de los parlamentarios que les confiere su calidad de representantes del pueblo español. ${ }^{13}$. En esta misma dirección, Gónez Bentez ${ }^{32}$ juzga como saludabie criterio la caracterización de la inviolabilidad como causa de justificación, axparada en el cjercicio de un derecho o un eargo, frente al cbsoleto y "privilegdado" de su consideración como causa personal de exclusión de la pena. En efecto, dentro del ámbito de cualquicer causa excluyente del injusto, hay que moverse siempe dentro de los limites establecidos.

29 Thickat, pp. $40-42$.

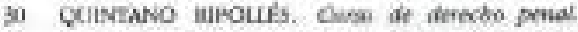

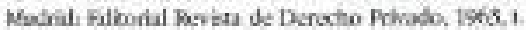
T, pp. $145-146$

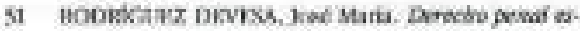

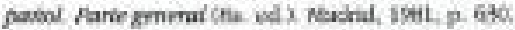

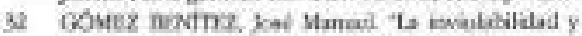

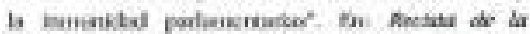

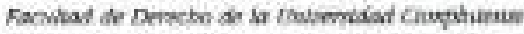

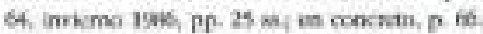

Consecuentemente, puede afirmarse con Gámez Benitez ${ }^{33}$-en lo que nos parece la tesis mis correcta-, que la inviolabilidud parlamenturia supone un "plus" respecto a la libertad de expresión que debe reconocerse a los ciudadanos; "plus' que viene referido a determinados delitos de expresion, que conculcan bienes juridicos protegickos de los que son clepositarias determintadas instiluciones. Peto dicho "plus" de liberiad estarí siempre sujeto a la "necesidad" de tales acciones para el curnplimierto de la función. Por ello, resulta dificil comprender que las manifestaciones calumniosas, por ejeanplo -tal y como ya pusaimas de manifiesto en un momento precedentes, pudieran ser "necesarias", en cl sentido antes asumido, para dicho ejercicio de la función parlamentaria.

L2 jurisprudencis del Tribunal Supremo mantiene este último criberio al considerar la inviolabilidad como una causa de justifi. cación, eliminatoria de la antijuricidad de la acción, por ampararse en el ejercicio de un derecho o cargo ${ }^{34}$.

Por bo demás, en cuanto garantía sustantiva que es la inviolabilictad, resultaria completamente desnaturalizada si se trasladara el requisito excepcianal de la previa autorización parlamentaria al ámbito de la invickabilidad; esta, como ya ha quedado expuesto, es una garantia sustartiva, no procesal, que, en cuanto excluye la resporrsabilidad juridica de los diputadios y senaklores por las opiniones manifestadas en el ejercicio de su función parlamentaria, no reguiere la interposición de una autori. zación previa, que solamente, al carecer de expresa consagración constitucional, podria introducinse a través de una especie de via analogica que no consiente la inter-

34 Hialcul, a 67 .

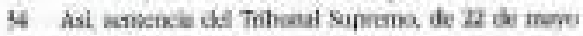
at 1991. 
posición estricta que merecen todas las prenogativas, las cuales no suministran fundamento constitucional para condicionar o impedir ta prestación de la función jurisdiccional con sutorizaciones pervias para proceder en el orden civil contra par. lamentario $6^{35}$.

En su sentencia 9/1990, el juez de la Constitución insistirta en la idea de lia incompatibilidad del instrumenso de la autorización parlamentaria, o suplicatorio, con la maturiteza y akeance de la inviolabiltdad $^{2}$. $X$, en otro monento, el Allo Tribana] consideraria que, siendo cierto que las parlamentarios $-a l$ igual que otras personas que intervienen en las contiendas po: liticas o son profesionales de la información- están expuestos al riespo de tener que soportar demilnatas civiles port parte de las personas que consideren que las opiniones manif́estadas por aquéllos entrañan intromisiones ilegftimas en sus dere. chos al bonor, a la intimidad o a la propia inagen, ello, sin embargo, no constituye justificación razonable y proporcionada para establecer, en el orden procesal civil, un requisito - en protección de los diputados y senadores- que, en manifiesta contradicción con lo dispuesto por el articulo 71 de la Constinición, pxoeda impedir el ejercicio del derecho a la nutela judicial, skudiendo al procedimiento de sustituir el privilegio de la inviolabilixbal por una exorIntante premogativa que traskada, mals allá de las previsiones constitucionales, la disponibilidad del procesa a un órgano no ju. ficial $y$, con ello, la de la potestad jurisdicclonat de contrular, sin injerencias extrañas, el uso que los parlamentarios hagan de su

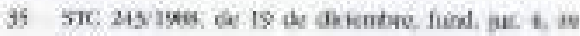
jine

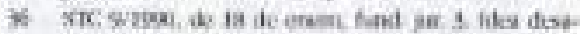
matu on alland is 4 libertad de expresibon y la aplicación al mismo de la garantia de la inviolabilidad".

\section{LA INMUNIDAD PARLAMENTARIA}

\subsection{Concegono y delimitaciôn}

La inamunidad ha sido definida por muestro "intérpete supremo de li Constitución $n^{196}$ como una prerrogutiva de naturaleza formal que protege la libertad personal de los representantes populares contra detenciones y poccesos judiciales que pueden desembocar en privacion de libertad, evitando que, por manipulaciones politicas, se impida at parlamentario asistir a las reuniones de las Cilmans $y$, a consecuencia de ello, se saltere inclebidamente su composición y funcionumiento. Al servicio de este objetivo se establece la autorización del óngano parlanientario para proceder contra sus miernbros, que es un instrumento propio y caracteristioo de la inmunidad, cuyo campo de acfuación se limita al proceso penal una vez desaparecida de nuestro ondenamiento la prislón por devdas y la privación de la libertad derivada de actos administrativos.

Como ya tuvianos opoctunidad de senialar con caricter gencral para todas las premogativas parlamentarias, ta inmunidad no es un privilegio personal, esto es, un instrumenta que ínicamente se establece en beneficio de las personas de diputados o senabores al objeto de suatraer sus conductas del conocimiento o decisión de pue. ces y tribunales. 1a inmunidad, al igual que ta irviolabilidad, se justifica en atención al econjunto de funciones parlamentarias respecto a las que tiene como finalidad

97 lisabst, hond. pur 5.

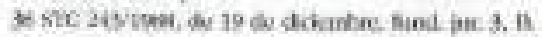


primordial su proteccions, De shi precisamente que el ejercicio de ia facultad concreta que de la inmunidad deriva se baga en forma de decisión que la totalidad de la Cámara respectiva adopta.

La inmunidad, en suma, puede ser considerada, como ha reconocido el juez de la Canstinucion" como la expresiden asis catracteristika de la inviolabilidad de las Contes Generales que, de modo rotundo, proclama d artículo 60.3 de nuestra Lex superion.

Es elaro, a la vista de todo lo expuesto sobre la inmunidad, que este instituto no se orienta a la protecoción frente a la improcodencia o falta de furdamentación de las acciones penales dirigidas contra los diputados o senadores, poes no cabe mayor defensa treme a tales riesjgos o defectos de tipo furiddico que la proporcionada por los jueces y tribunales a quienes al articulo 117.1 de la CE stribaye, de manera espectfica, la tarea de aplicar el ordenamiento para la administración de justicia. Poos to mismo, como ha sentalado el Tribunal Constitucional"s, ila amenaza frente a la que jowege la inmunidad stólo puede ser de tipo poiblica, y consiste en la eventualidad de que la via penal sea utilizada con la intención de perturbar el funcionamiento de las Cámaras o de alterar la composición que a ellas ha dado la voluntad popular. La posibilikdad de que las Cámaras aprecien y eviten esa intencionalidad es lo cye la Constitucice ha querido at otorgarles la fa. cultad de impedir que las acciones penales contrat sus miembros prosigan, $y$ lo que permile - por tanto- la institución de la inmunidad es que las propias Camaras realicen algo que no pueden llevar a cabo los organos de naturaleza jurisdiccional, como es una valoración sobre el significado politico de tales acciones.

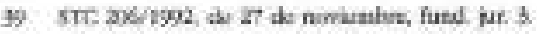

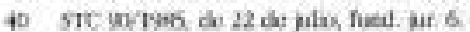

La hipótesis de una intencionalidad hostil a la institución parlanentara en la actuación judicial, determinante en los origenes del instituto (fiamas persacutonis), debe ser hoy considerada, siempre a juicio del Aito Tribunall, un supuesto no descartable, bien que su capacidad de agotar el seritido del instituto supondría la restriccion del mismo a unos límites que no parecen haber sido los queridos por el constituyente. tgualmente, es clato que la inmunidad no ha sido concebida para operar, de facto, una extensión de los limites de la prerrogativa, en parte vecina, de la inviolabilistad. Mucho menos ha sido preservada por el constituyente de 1978 para generar zonas inmunes al imperio de la ley. Sólo ese sentido institucional de la inmunidad a que antes aludiamos -esto es, solo la salvaguanda, a través de eata garantia, del interts superior de la represientación nacional de no verse alterada ni perturbada, ni en su couposición ni en su funcionamiento, por eventuales procescos penales que puectan incoarse frente a sus miembros por actos produclidos tanto an tes como durante su mandito-, es susceptible de preservas la legitimidad de esta premogativa.

Ahora bien, ese significado instifucional no debe ser entendido en el sentido de que aquel interés superior de la representación nacional deba imporierse, en todo caso, a la prosecución de la acción de la justicial. $Y$ asi, si la inmunidad quedase a merced del puro juego del respectivo peso de las fracciones parlamentarias, ta institución resultaria inequivocamente desnaturalizadia $x^{42}$.

Esta afimación no debe entenderse en el sentido antitétios de que siempre que se requiera un suplicatorio a una Camara par-

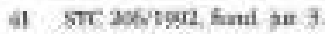

a thades 
Lamentaria ésta venga olstigada a concederlo para peratilir el acceso a la fusticia ${ }^{\text {33 }}$. Es preciso, por el contrario, reconocer en el Also Tribunal ${ }^{46}$ que $\mathrm{ta}$ inmunidad implica siempre una posibilichad de que sea denegado el derecho al proceso penal ${ }^{45}$. Quizal la clave para encajar los distintos derechos y bienes constitucionales en juego sea el atender -al margen ya de la existencia de una amenaza, frente a la instirución parlamentaria, de intencionalidad politica- a la gravedad, trascendencia y circunstancias de kos hechns imputados ${ }^{k}$.

Aunque es consante la práctica parlamentarla de coaceder o denegzar suplicatotoos en base al criterio apriorista del tipo de delito, concoedamos con Fernández Miranda $a^{7}$ en la inadecuación de la misma al fun-

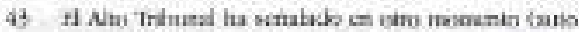

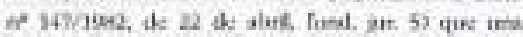

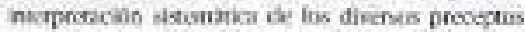

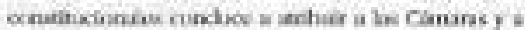

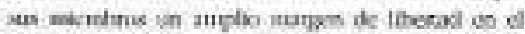

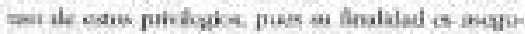
ar a besn funckonations de be inotiouckons par

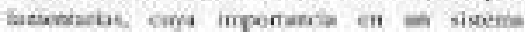
dunarikion es deciswa

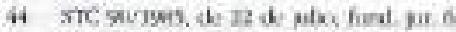

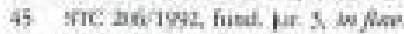

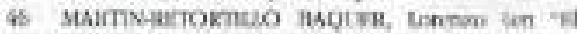

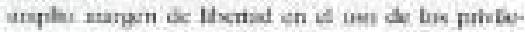

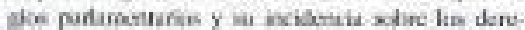

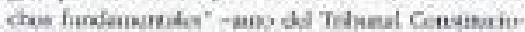

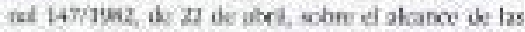

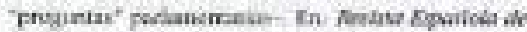

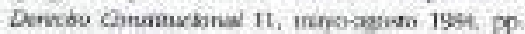

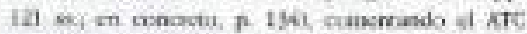

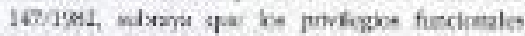

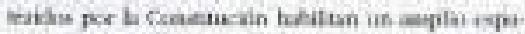

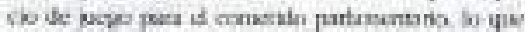

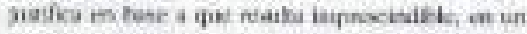

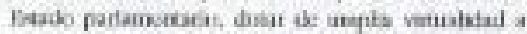

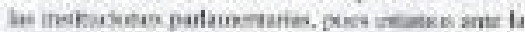

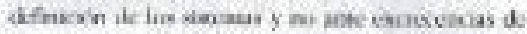

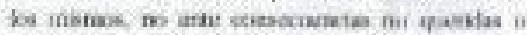

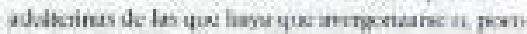

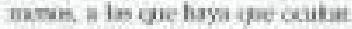

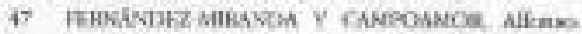

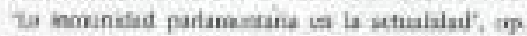
(k, p. 245 damento de esta prerrogativa. Por otro lado, como bien se adviertelli, el criterio de ta gravedad de la infracción imputada al parlamentario plantea serias dificultsdes, pues, doóro encontrar un elemento, prociso juridicamente, para distinguir la granedad o levedad de una infracción' Es por ello por lo que, desde la seguridad juridica, este criterio parece dificilmente defendible.

In definitiva, es indliscutible que las peopias Canmaris, en uso de si libertad, están llamsalas a asumin un procagonismo evfdente en el logro de un perfil canstitucionalmente adecuoda de la institución, pero lo que naria debe olvidane es que tambien a ellas les alcanza ed principio constitucional de interdicción de la arbitrancedad.

\subsection{Naturaleza juridica}

Existe una posicion doctrinal maycriwria que entiende que la inmunidad es un instiruto de derecho procesal penal, una candición de procedibilidad.

De tal naturaleza derwa, como seriala Pizzoeusso ${ }^{49}$, el que la inmunidad opera exclusivamente en el dimbito del proceso, de modo que la falta de concesión de la autorización no impide la reinterpesicián de la acción una vez que el obstículo haya dessparecida por la conclusicen del periodo de sestiones o de la legislatura, por la dimisión o caducidad del mandato, etc. El propio alutor, en otro lugar 39 , significa que ao estamos ante una exinente $y$ si sólo an te una causa temporal de improcedibilidad de la aeción penal, acción que quecla diferida en su cfoctividad hasta el momenta en que se conceda la autorización parlamen-

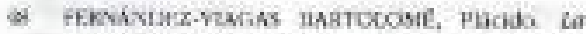

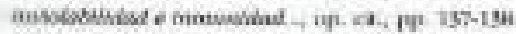

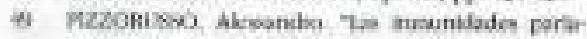

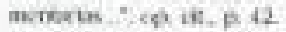

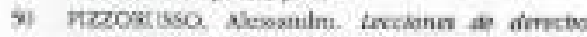

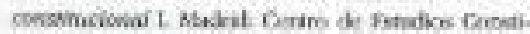
aucionalen, 1sens, n. 278 . 
taria o -en șu defecto- hasta el têrnino de la legistatura, a no set que se produzca la reelección.

En suma, la inmunidad no sería una causa de exclusión de la responsabalidad penal, como boisicamente lo es la inviolabilidad, sino una causa de suspensión del proceso penal, que lleva aparejada la suspensićn de la prescripción del delito ${ }^{51}$. Como en análoga dirección advierte Rodriguez Devesa's, cuando el diputado o senador pierde su condición de tal, cesa de operar el óbice procesal.

Esta naturaleza se sustenta en la propia funcion constinucional del instituto en cuestion: st, como hemos significado con anterioridad, la inmunidad ampara la funcion, no del parlamentario individual, stno del conilunto del Parlamento, si no esizmns ante un privilegio personal, sino ante un instrumento de salvaguarde del instrumento del conjunto de funciones parlamen. tarias, parece lógico conchuir que, una vez el parlamentario deje de serko, desaparecerí el obstácula que inpedía proceder contrat ell.

Ello no obstante, en nuestro ordenamiento juridico existe un impedimento frente a til conclusión. Ir ley de 9 de fe. brero de 1912, por la que se regalan la juriscliccion y el modo de proceder constri senadores y diputados por raxón de delito, dispone en su articulo 7 , inciso primsero, que: "si el Senado o el Congreso denegise La autorización para procesar, se comuricará el acuerdo al tribunil requirente, que dispondita el sabrosimiento Nbwe respecto al senador $O$ at diputado". $Y$ a tence del

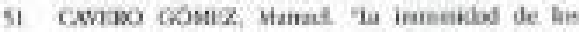

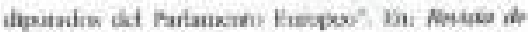

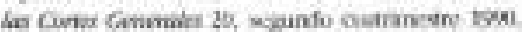

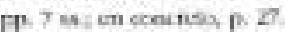

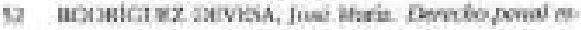

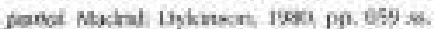

articulo 637.3 de la ley de Enjuiciamiento Criminal, el sobreseido queda exento de responsabilidad criminal. De modo que el sobreseimiento libre supone en la prictica el arcbivo definitivo de la causa $y$ la imposibilizlad de reabrirla una vez expirado el mandato parlamentario

Por lo mismo, el libre sobreseiniemto supone trastocar la naturaleza juridica cle la inmusidad, que de esta forma deja de ser una causa de improcedibilidad para urastomiarse en una causa de exclusión de li responsabilidad penal, trastormación Esta de mis que dudoso acomodo al signnificado del artículo 71.2 de la $\mathrm{CE}^{33}$. Como bien significara Carro Martinez ${ }^{4}$, la inumnidad concedida debiera intemumpir al plazo de prescripción del selito imputado, de manera que una vez cesada la función parlamentaria no quedara consagrada la impunidad. $\mathrm{Y}$ en análoga dirección, $\mathrm{GO}$ mez Benitez ${ }^{55}$ cree que la denegación del suplicatorio no produce efectos materiakes de exención de responsabulidad, sino sólo de imposibilidad temporal de proceder penalmente contra el parlamencario mientras dure su función, es decir, su statis

No obstante lo discutible de ja fómula legal de 1912, el juez de la Consticución ha sido especialmente cauto al respecto at limitarse a constatar que, por bor del articulo 7 de la citada ley de 1912 , el sobre-

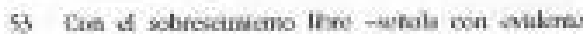

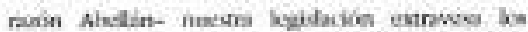

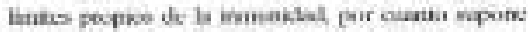

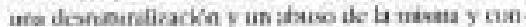

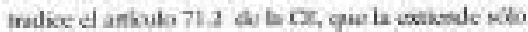

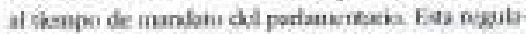

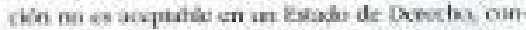

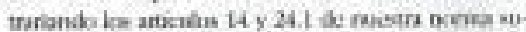

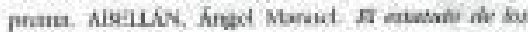

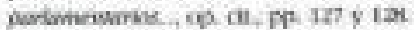

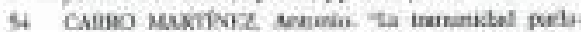

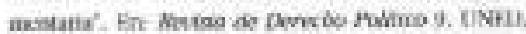

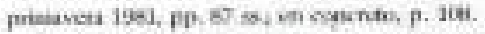

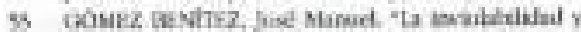

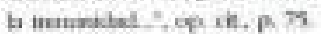


seimiento libre de actuaciones impide la posibilidad de un nuevo procesamicnto, pues tal sobreseimiento implica las efectos de cosa juzgada material ${ }^{56}$

La distuncionalidad de la fórmula legal acuñadia en 1912 se pone aùn más de maniflesto si se advierte que el artículo 754 de la ley de Enjuiciamiento Criminal se limita a establecer la procodencia de declarar el sobreseimicnto cuando se deniegue por una de las Cåmaras la autorización para procesar, obviando toda referencia al sobreseimiento libre.

\section{Sujetas de esta prerrogatiea pariamentaria}

Las instituciones de la inviolabilidad e inmunidad aparecen recogidas y referidas, en el articulo 71 de la Constitución, tan sioto a los diputados y senadores. Nuestra norma suprema sio acoge -como hatce, por ejemplo, el artíctilo 122 de la Constitución italiana respecto a la inviolabilidad- la menor referencia a los miembros de las asambleas legislativas de las convinidades autonomas, cuestican que es objeto de regulición por los estatutos de autonomsa corespondientes.

Este silencio constitucional esta en la base de la problemática interpretativa surgida en relación con ta posibilidad de extender la inmunidad parlamentaria, mais alla de las propias previsiones estatutarias, a los miembros de las referidas asarnbleas legislativas.

E. Tribunal Constitucional abordaria esta cuestion con ocasion del recurso de inconstitucionalidad contra ta ley de la Comunidad Autonoma det País Vusco, 2/1981, de 12 de febrero, sobere reconocsmíento de derechos de inviolabilidad e

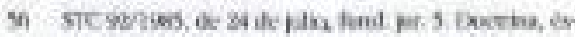

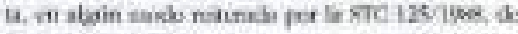
24 or junis, final, in + . inmunidad de los micmbros del Parlamento vasco, recurso resuello mediante ia sentencia $36 / 1981^{57}$.

FI articulo 26.6 del Estatuto de Autonomila del Pais Vasco acoge el instituto de la inviolabilidad de los parlamentarios en términos similares a como se conternpla el mismo a nivel del Estado; sin embargo, en lo cye bace is la inmunidad, el Estatuto conticne una fócrmula menos amplis que ta del articulo 71.2 de ta CE, en cusmo omite la referencis a la inmunidad en sentida genérico y no recoge la necesidad de suplicatorio o autorlyacion de la asamblea legislativa para inculpar y peocesar a sus miembros, aunque se les reconozca el no poder set detenidos, salvo en caso de flagrante delito, y un "fuero especial" consistente en atribuir la competencia al Tribunal Superior de Justicia del País Vasco o a la Sala de lo Penal del Tribunal Supremo, seguin loe casos, para decidir solare la inculpación, prisión, processamienzo y juicio "de low miembros del Parlamento vasco".

Frente a las anteriores deterninaciones estatutarias, la ley $2 / 1981$, de 12 de febrero - ya citadi-, incluia en su anticulo 2 las siguientes ampliaciones respecto del regimen establecido por el articulo 2666 de la norma estatutaria: a) se recoge expresamente la "inmunidad de los parlimentarics durante el periodo de su mandato" b) se prevé la nocesidad de "suplicatorio" otorgado por el Parlamento vasco para inculpar y procesar a sus miembros, $Y$ ol se requiere la previa autorizaciốn del Parlamento "para continuar las actuaciones juxilciales respecto de quienes, hallandose procesados o inculpados, accedan a la condicićn de parlamensarios".

Al guardar silenxio b Canstitución sobre las prerrogativas parlamentarias de las. miembros de las asambleas legislativas

57 se hylsel, de 12 de ninkembre. 
sutonócnicas, han sido los estatutos de autonomia, en cuanto "norma institucional básica" de la Comunitad Autónoma (art. 147.1 de la CE), el lugar adecuado para regular el status de los poirlamentatios en cuanto 3 la inviolabilidad $e$ inmanidad de los mismos se refiere.

Asl las cosas, es patente que la ley 2/1981 modifici sustancialmente cl sistema sancionado en el Estaruto de Autonomia del Pais Vasco en la parte relativa a la inmunidad de los miembros del Parlamiento de dicha Comunidad Autonoma. En efecto, como advierte el juez de la Consttución ${ }^{56}$, mientras que el Estasuto reconoce a tales parlamentsios una inmunidad parcial o limitada ("no podrán ser detenidos ni retenidos, sino en caso de flagrante delito'), ba ley $2 / 1981$ amplia esa prerrogativa, de manera que la convierte en una inmanidad plena o completa.

Tal ampliación de la inmuniclad por una ley de la Comunidad Autónoma vasca supooe la modificación del Estatuto de Autonomia por un cauce distinto del previsto tanto en la Constitución como en el propio Estatuto y, port ello mismo, dicha ley es tildada de inconstitucional y antiestatutaria, calificación esta ultima que, en realidad, queda comprendida en la anterior. Fs por lo expuesto por lo que el juez de la Constitución declara la inconstitucionalidad y consiguiente nulidad, entre otros preceptos de la citada ley 3/1981, det articulo que procede a ampliar la inmunidad de los parlamentarios vascos en los términos ya referidoss.

Con ello, como el Tribunal ha roconocido en ulteriores pronunciamientos $\%$, se declaraba inaplicables a las miembrus de los Parlamentos de las comunidades auto-

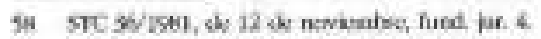

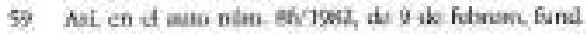
bir. uิเมี⿻. nomas las preceptos del artículo 71 de la Consticución, exclusivamente referidos a las de las Cortes Generales, doctrina reiterada con posterioridad ${ }^{60}$, bien que con ta precisión de que la inmumidad es una pre: nogativa que, a diferencia de otras parlamentarkas, es privativa y exclusiva de los miembros de las Contes Generales de la nación españols.

Esta jurisprodencia sería juzgada positivamente por Pizzorussod ${ }^{61}$ sobre la base de entender que la inmunidad no puede extenderse a sujetos distintos de aquellos a los que expresamente se contiere, si no es a traves de un acto normativo capaz de derogar las normas que escablecen la obligación de ejercitar la acción penal.

\subsection{Ambito material de la inmunidad}

La inmunictad parlanentarfa encuentra su ámbito de actuación en el peoceso penal, resultando una garantía inadecuada para impedit $e t$ curso de una demanda civit, por cuanto este instiruto excluye que su protección se extienda a procesas que no sean penales ${ }^{62}$. Queda así perfectamente delimitado el ambito material de la inmunidad parlamentaria, en lo que constituye, por lo demás, una reiterada doctrina constitucional, motivada, en buena medida por el intento del legislador de ampliar dicho Ámbito.

En efectos, b ley ongánica 3/1985, de 29 de mayo, de modificación de la ley orgánica 1/1982, de 5 de mayo, de protección ci-

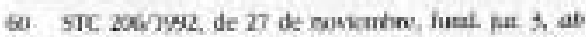
inino

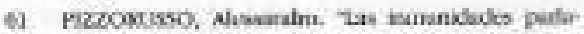
comiarias..; ap cit-ip 43 .

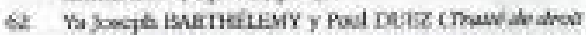

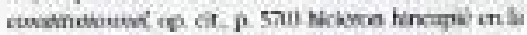

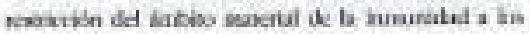

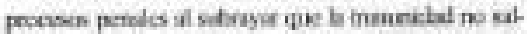

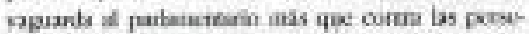
oxhones nprowas pre craten st jer dethi, por bo que eta garath no obotaculta bo aximes strils. 
vil clei derecho al honut, a la intimidad personil y familiar y a lis propla imagen, agregó al aribculo 2.2 de esta última norma legal la siguiente disposición: "fno se aprocians la existencia de intromisiobn ilegitira en el âmbito protegida..l o por inperativo del astículo 71 de la Constitución, cuando se trate de opiriones manitestadas por dipucados a senadoes en el cjercicio de sus funciones. Insiciado un proceso civil en aplicación de la presente ley, no podrí seguirse contra un diputado o senador sin la previa autorizicián que serí tramitada por el prooedimiento previsso para los suplicatorias".

Un recurso de amporo prominich frente a la denegacion -por el Senado- de autoriación para la prosiecución de acruaciones por un Juzgado de Primera Instancia, inictadas por detranda civil frente a un senador al amparo de la ley $62 / 1978$, posibilitaba la primera $\rightarrow y$ muy clara- toma de postura jarisprudencial al respecta.

E juez de la Constitución manifestatia que, conforme a lo dispuesto por el articuto 71 de la CE, la unica prerrogativa partamencaria que puecle justificar la suspensión de las actuaciones judidales, en buto b CAmara se pruntincia concediendo o denegando la 'pecvia autorización', es la de la inmunidad, pues unicamente es esta institucicin la caie constitucionalmente permite la exigencia de dicho presupuesto procesal. Sin enlxargo -aniadia el Tribunalos la inmunidad parlamentaria se manficas inapropiada para impedir el curso de una demanda civil interpuesta contra un parlamentiro, pues el senticho propio de las palabras empleadas por el articulo 71 de ia Constitucicinth, los antecedentes histónicus y legisiatwas de esa prerrogariva de los miembros de las Camaras, y la razón misna de la instinicioni exduyen, cun absuluta ctarialad, que

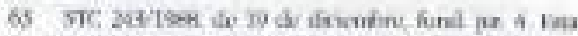

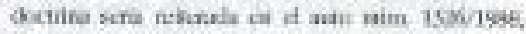
de 19 dediander, fint pir. 2 h. su precección se extèenda a procescos que no sean perales, $\propto$ decir, que no entra en la eventualidad el que sean utilizados con la intención de perturbar el funcionamiento de la Camara o alterar su composición me. diante la posible privación de libertad del parlamentario.

Se sigue de ello que la "previa autorizacodn" que requicre el articulo 71 de la Constitución para inculpar a ptocesir a diputados o sensidores no puede exigirse pait la admissón, tramitación y resslución de denuadas civiles que en nada pueden afectir a su libenad personal, y, en consecuencia, que la extensión al sumbito civil de dicha garantia procesal resula constitucionalmente liegitima ${ }^{65}$

En suma, la doctrina del Trabunal venia a reconcoer la inexistencia de fundamento constituclonal para condiclonar o impedir la prestación de la función jurisdiccional con autorizaciones previas para proceder en el orden civil contra parlamentarios. En sintonis con ello, el Tribunal consideraba que los demandantes de amparo habian visto vulnerado su derecho a la tutela judicial, procediendo al unisono la sala que conocis del amparo 2 elevar la cuestion al Pleno del Tribunal a fin de que pudiera proounciarse sobre la inconstitucionalidad def precepto anteriormente trascrito.

In nuevo recurso de amparo motivado por una nucva denegación de suplicutorio para que un Juzgado de Primera Instancia continuara actuaciones judiciales sobre

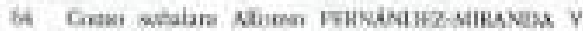

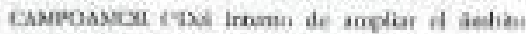

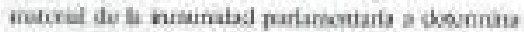

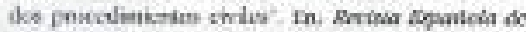

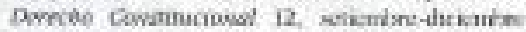

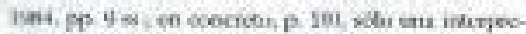

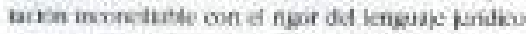

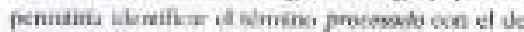

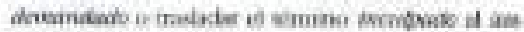
hen dol deratos cont

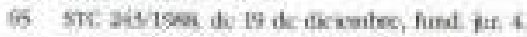


derecho al bonoc, frente a una diputada, daba pie a ctro pronunciamiento del Alto Tribunal en tếrminos muy stmilares a los anteriognente expuestos ${ }^{65}$.

El Tribunal comenzaria precisando que en el caso en cuestión no se estaba propiamente ante el instituto previsto en el artículo 71.2 de la CE, esto es, ante la inmunidad con que la Constitución protege a los parlamentarios frente a inculpaciones y procesamientos, sino ante el peculiat expectiente introducido por la ley organica 3/1985 y en cuya virtud se exige una autorización "para la prosecución de las demandas civiles articuladas por la via de la ley orgànica 1/1992". Tras teiterar la doctrina expuesta en la sentencia 243/1988, el juez de la Constitución consideratia ${ }^{67}$ que no era tanto el contenido del acto parlamentario (denegatorio del suplicatorio), stno la exigencia misma de ese acio to que habia vulnerado el derecho a la tutela judicial del solicitante de amparo.

Finalmene, en su sentencia 9/1990, el Pleno del Tribunal resolvia la cuestión de inconstitucionalichal elevada al mismo por la Sala Primera del propio órgano ${ }^{6 \%}$.

Parte, el Tribunal, de bu finalidad a que responde el requisito de procedibilidad introducido por la ley orgdnica 3/1985, "que no es otro que el de proteger, a través de la zutorización parlamentaria previa, a los dipurados y senadores de la constante amenaza de demandas civiles a que pueclen verse sometidos a consecuencia de las opiniones que expresen en estrecha conexión con sus funciones parlamientarias, que no se produrcan dentro de las sedes de las Camaras y a las que no alcanzaria ed principio de la inviolabilidad".

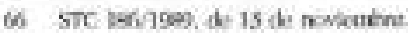

6 Avides, final an 2.

6. STC gissh de is de enes:
Seria suficiente -advierte el Tribunatity centrar la atención en la última frase para obtener, sin más razonamiento, la inconstitucionalidad de ess exigencia de autorización poevia, pues en ella se pone de manifiesto que el legistador, de manera consciente, amplía, mís allí de jos limites establecidos en la Constitución, el privilegio excepcional de la inviokabilidad, puesto que reconoce expresamente que la finalidad del roquisito procesal es la de extender la inviclabilisdad a supuestos excluidos por la Constitución del ámbito de esta garantia, y ademis lo hace apticando a b misena el instrumento del saplicatorio, que nuestra nomia suprema solo permite utilizar como garantía de la inumunidad y que es, por ello, incompatible con lu naturaleza $y$ alcance de la inviolabilidad, como ya tuvimos opartunidad de exponer cusndo nos referimos a esta ditima prerrogativa.

El legistador parece ignorar algo tan elemental como que bs prerrogativas no scon privilegios al servicio de intereses privados, sino que tienen un fundamento institucional que trasciende los intereses particulares de sus beneficiarlos, para servir un interés superior del ordenamicnto juridico.

En definitiva, el legistador en sede onganica introduce, a través de una noma extensiva del articulo 71 de la CE, una autorización previa que dicho precepto sólo consiente en los procesos penales, creándose asf una instituciôn hilhricta, compuesta a partir de elementos conceptuales de ba inviolabilidad a los que se antade un instrumento autarizatorio, propio y exclusivo de Lit inmunidad, que carece de encrie constitucional y conileva una irraxonable $y$ des propoccionada limitación del derecho a la tutela judicial en cuanto impide el ejercicio independente de la purisdicción y, pot tanto, resula desprovista de la debida justifi-

(i) Thadem funt ar, 3 
cación. Obviamerte, coano corolario de la anterior, el Tribunal declara la inconstitucionalinad $y$, por consigujerte, la nolidad de la adición al artículo 2.2 de la key orgánica $1 / 1982$, realizada por la ley orginkea 3/1985.

\subsection{La incidencia do esta premogarita saibre el chrecbo a la futela jucticial gectira y su necesario controi an sode constituctional}

La inmunidad parlamentaria -como deja muy en claro el artículo 71.2 de la CE-se concreta, ante todo, en la exención de cualquier posible detención si no es "en caso de flagrante delito", A cllo se anade la garantia de no inculpoción ni processmiento 'sin la previa autorizacion de la $\mathrm{C}$ mara respectiva:. De este modo, como reconoce el Tribunal? ha verido a incorporar un insítuto que en la modida en que puede suponer und poralización, siquiera temporal, de la acción de la justicia $y$, en sa caso, del dere. cho fundamental a la tutela de los juecesaparece frima facte como una posible exocpcica a uno de los pilares básicos del Estudo de Derecho: "el sometimiento de todos at imperio de la bey como expresión de la voluntad popular' (Preimbula de ta Constiruciôn de 1978). Astí las coctas, es evidente que el instituto de la inmunidad exige ser comprendido en el manco global del sistema constitucional.

Es una obviediad -en todo caso, de necesario necordatorio- que, desde una pers pectiva matertal, Ios preceptns que integran la Constitución son todos ellos conssitucior nales y, exmo ales, gozan del contenido y de la eficacia nomativa que de so respectiva dicción resulta. Par cern bado, es tainbién una evidencia que "la Constipución no

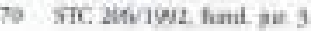

es la suma $y$ el agregado de una multiplicidad de mandatos inconexos, sino precisamente el orden juridico fundamental de la comunidad politica, segido y orientado a su vez por la proctanacion de sa artículo 1.1, a partir de la cual debe resultar un sistema coherente en el que todos sus contenidos encuentren el espacio y la eficacia que el corstizuyente quiso coforgatles 71

El sistema constitucional, por lo demás, es ajeno a cualquier concepción jerarquszada - cle forma más a menos latente- entre sus contenidos "dogmatico" y "orghinico". Derechos fundamentales y estructura demncrática son, sejuon el Tribunal, experesiones y sopante del mismo y único modelo de comunidad política que, desde sus origenes, la Constitución representa.

La Constinución, sin mayores especificaciones, se limita a recoger la figura de la inmunidad de los diputados y senadores "durante el periodo de su mandato". Deja asi a indos sus destinatarios, en su distinta responsabilidad, el empeno de concretar, y de actualtar, "un instituto caracteristica. mente vinculado -según el Alto Tribunal-a las condiciones histónicals de ifirunción y de consolidación del Fstado de Derechot:

Fleconoce el Tribunal que en esti tarea estin particularmente implicadas las proplas Cámaras, muy en especial a través de su tarea constante de formoción de unos usos parlamenarios consustanciales al ré-

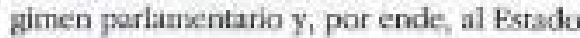
de Derechio.

Aunque en la facultad que el ariculo 712 de la $\mathrm{CE}$ atribuye a Las Camaras, de conceder o no la autorización para encau. sar por via penal a sus miembros, aquellas pueden disponer libremente, ello no supone; sin embargo, que el litre exercicio de esta facultad quede exento del principio cle sometimicnto a la Constitución, que,

7) foldin 
con carácter yeneral, impone el artículo 9.1 de li misma a las poderes públicosi.

En virtud del referido principio, cualquier acto juridico del Parlamento, con rebevancia juridica externa, esto es, que afecte a siruaclanes que excedlan del ámbito estrictamente propio del funcionamiento in-

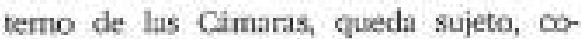
menzando por los de naturaleza legislativa, no solo a las normas de procedimiento que en su caso establexca lat Constitución, sino, asimismo, al conjumto de normas materiales que en la misma Constitución se contienen. Por ello mismo, el Alto Tribunal entiende ${ }^{72}$ que no puede aceptarse que la libertad con que se produce un acto parlamentario, con esa relevancia jurídica para terceros, legue a rebasar el marco de tales normas, pues ello, en nuestro ordenamiento, seria tantro como sceptar la arbitrariedad.

En cuanto que la facultad que deriva del artículo 71.2 de la CE es ejercida por una Cámana mectiante actos o acuerdos singulares sin tuerza de ley, y en cuanto que no cabe rechazas, por principio, la posibilidad de que los mismos lleguen a vulnerar los derechos y tibertades que, según el articulo 53.1 de la CE, vinculan a todos los podkres públicos, nual es, muy signifi. cativamente, el supuesto del derecho acogido por el anticulo 24.1 de la norma soprema, es patente la posibilidaxd de revisar, desde la perspectiva constitucional, los actos de las CAmaras por kas que, en libre ejercicio de la prerrogativa de la inmunidad, se resuelve acerca de la solicitud para procesar a alguno de sus miembros.

No en vano la dispanibilidad del proceso penal se convierte en el objeto uillino sobre el que deciden las criganos parlamentarios, de los que no puede afirmarsc, en consecuencia, que sean ajenos a la prestacion de tu tutela judicial. Bien al con-

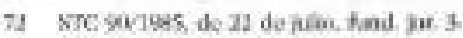

trario, ésta dependert, en último término, de una actuacion parlamentaria (la que conceda a deniegue el suplicatario), actuación que adquiere relieve furisdiccional y es, por tanto, susceptible de exainen desde la perspectiva del artículo 24.1 de la $\mathrm{CE}^{75}$. Es obvio, por lo misano, que habríl de ser el Tribunal constitucional quien, cuando sea requerido para ello por la via y con los requisitos del amparo constitucional, lleve a cabo el control constifucional mediante el examen del caso concreto.

\subsection{El contral constitucional dol sucticatorio}

Acabanos de sehalar que la posibilidad de conceder o denegar suplicatorios para procesar a diputados o senadores - en que la institución de la inmunidad se concretaquecla estrechamente vinculada a la futrción de impartir justiciaj en tal aseclida, parece logico que le sean aplicables, a la hora de su coctrol en sede constituciomal, tos parimetros del arículo 24.1 de la Constitu. ción.

Elio no significa que el acceso at la justcia deba prevalecer en todo caso, obligan. do a las Camaras a conoceder el suplicitorio. Una interpretación de este pénem, ademís de ignorar que ta Constitución -como ya dijimos es un todo que ha de ger interpretado de modo armónico, vaciaria cie conterido el instituto de la inmuntdad. Además, no hay derexhos absolutos $y$, por lo que hace al mandato del articulo 24.1 de la CB., es doctrina retierada del "interprete supremo de la Canstitución", que de dicho precepto no deriva un dere: cho incondicionado a las distintas acciones. processales.

Constituye, de igual forma, una consolidada doctrina constitucioesal, que el artiou-

83 STc poisss bind in a 
lo 24.1 debe aplicarse en cada caso seguin la naturaleza y fines de cada tipo de proce. dimiento. En esta doctrina -como el propós jues de la Constitución reconoce ${ }^{74}$ late un acentuado carbeter finalista, impticando que las linitaciones del derecho a la jurisdiccion hayan de aparecer justificadas por la ratio de las distintas instituciones procesales en que tales limaticiones se producen.

El traslado de esa cloctrima a la técnica de los suplicatorios supone que la denegación de los mismos haya de considerarse comecta, desde la perspectiva del articulo 26.1 de la CE, unicamente en el caso de que dicha denegación ses conforme a la finalidad que la institución de $b$ inmuniclad parlamentaria persigue y en la que la posiLilidad de denegaición se funtamenta, Por el conirario, si la denegación del suplicato rio se utiliza pard fines ajenos a la premogativa de la inmunidad, existiri un abuso de esta figura constitucional.

Ya hemos señalado que la amenaza frente a la que protege la inmunidad sólo puede ser de tipo politico, y consiste en la eventualidad de que la via peral sea utilizada con la intención de perturbar el funcicnamiento de las Cámaras o de altesar la composición que a ellas ha dado la voduntad popular. Por lo mismo, como de igual forma ya expusinos, ante esa eventualidad el constituyente ha querido otorgar a las Camaras la facultad de aprectar la existencia o no de esa intencicnalidad politica, atgo que escipa a la labar de kos ćrganos jutisdiccionales.

El criterio de caracter politico del becho, entendido de un modo laxo, condu. cirla en la práctica, como constata Pizroru$\$ s 0^{75}$, a constituir un átea de inesporisabi-

74 lledali tund ix. 6.

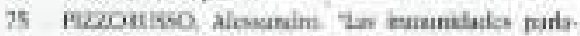

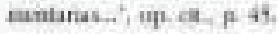

Iidad adicional respecto a lo previsto para las opiniones expresadas en el ejercicio de las funciones parlamentarlas. Sin enbargo, al Trilsunal Constitucional ha introducido en nuestro pais una serie de matices al efecto.

Considera el juez de la Constitucion? que, aungee el conirol que al propio Tri. bunal corresponde no puede llevarle a revisar o sustituir aquella valaración politica verificada en sede parlamentaria, sl je posibilita, por el contratio, la constalacion acorcat do st w fuicio de cportunidad o de intencionalidad se ba producido on las Camaras, y ello de modo suficiente, ste ex, en tifrminas razonables o argumentales. De la existencia o inexistencia de semejante juicio depende que el ejercicio de esal facultad parlamentaria se haya realizado cunforme a su propia finalidad, y depende, por consiguiente, en el supucsto de que ta decisićn parlaumentaria sea contrarial a permitir dicha futels, que el derecho fundamental a ésa haya de considerarse o no vulnerado.

A partir de esta cloctrina, en el "Caso Barral" -resuelto por sentencia 90/1985-el Tribunal atiende a varias circunsancias concretas:

- En primer térnino, al hecho de que el acuerdo del Pleno det Senado por el que se deniega la autorización para procesar al senadox don Carlos Barral aparece desprovisto de motivación alguina, inexistente de igual forma en has alegaciones formuladas ante el Tribunal por la representación de las Cortes Generales.

- In segundo lugar, a las propias circunstancias de la querella: ocasicnada por un escrilo de carnicter estrictamente Literatio del que ena autor don Carios Barrai, que salemis solo accederia a la

7 me geast, fand ius. 6 . 
Cámara Alta can pasterioridad, no concurriendo ningún elemento que pernitien apreciar, en li interposición de la querelly, la existencia de móviles o intencionalidades politicas.

A la vista de todo ello, el Alto Tribunal entendería que la denegación del suplicatorio por el Senado atparecía del todo desvinculada respecto a la finalidad que pudiers justificar la restricción del derecho * la tutela judicial efectiva del articulo 24.17 , fallando en el sentido de otorgar el amparo solicitado, con la sulviguiente declaración de rulidad del acuerdo del Pleno del Serado por el que se denego la autorización para procesar al senador doci Cartos Barral. La doctrina sentada poe el juez de la Constimución en 1985, no puede circunscribirse a la argumentación de que basta con que el Pleno de la Cimara proceda a motivar su acuerdo denegatorio de la concesion del suplicatorio ton base a la apreciación de una imtencionalidad o significación politica (perturbar el funcionamiento o composición de la Carmara) en la acción peral emprendida contra uno de sus miembros- para que ya el Tribunal, en uso de si solf-nstraint, liaya de limitarse a convalidar la conformidad constitucional de aquella valonacion verificada en sede parlamentarla, tesis ésta que parece susten-

$\pi$ streyoraws, find on 7, in fine

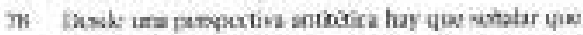

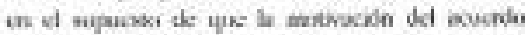

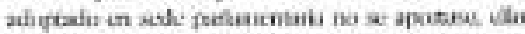

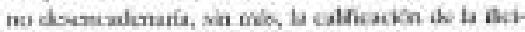

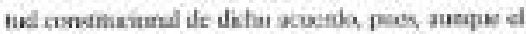

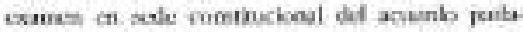

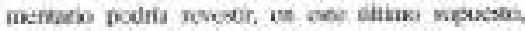

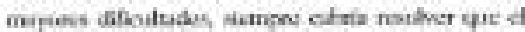

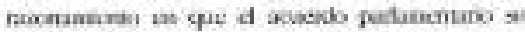

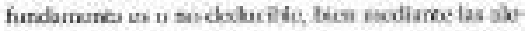

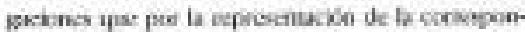

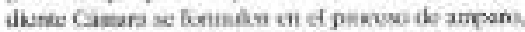

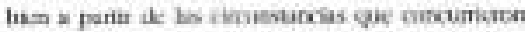

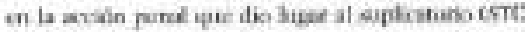
sulges, fund gar 71 tar -en su voto particular a la sentencis 206/1992- el magistrado don Álvaro Rodriguez, Bereijo $7^{79}$ cuando, especialmente, afirma que lo que el Irlbunal no puede hacer es revisar o sustituir esa valoración o juicio de oportunidad o intencionalidad de la Cámara por el suyo propio, suplantando a esca en una función que la Constitución (art. 71.2) le ha encomendado expresamente,

Ciertamente, en la sentencia $90 / 1985^{10}$ el Alto Tribunal admite que el control que en el caso que nos ocupa le corresponde no puede llevarle a revisar o a sustituir la valoración llevada a cabo en sede perlamentaria; pero de inmediato sration que "sí lpuede [levarle] a constatar que el juicio de oportunidad o de intencionalidad se ha producido en las Camaras, y ello de modo suficiente, esto es, en témninos razonables o irgumentales*, Lo contrario, a nuestro modo de ver, equivaldría a la renuncia de todo control constitucional por quien esta cblighedo a realizailo cuando sea instado a ello.

Ya nos bemos referido con anterioridad al principōa del "mayor valor" de las derechos fundamentales. En tal principio encuentra au apoyatura la doctrina constitucional en atención a la cual cualquier acto por el que se costa el libre ejercicio de un derecho constitucionalmente reconocido se considera que es de tal gravedad que "necesta encontrar una especial causaliza. ción", por to que el hecho o canjunto de hechos que to justifican deben explicarse con el fin de que los destinatarios conozcan las mazones por las cuales su derecho se sacrifico $y$ los intereses a los que se sacrifico. De este modo -oomo advierte el Tribunat ${ }^{\mathrm{EL}}$ - - la motivación no es solo una

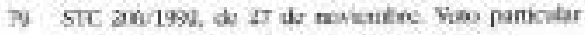

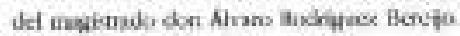

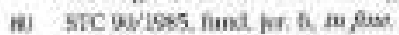

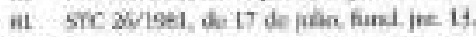


elemental cortesia, sino un riguroso requisito del acto de sacrificio de kas derechos".

El sacrificio del derecbo no puevie ser frito de una odecision arbitraria, sino que ha de responder a una determinada fina lidad que ba de asentarse on una justhycación razonable. En el caso que nos ocupa, es claro que la razonabilidad de la fo. nalidad nos viene dada poe la funcióa constitucional que desempena el instituto de b innuniclad: salvaguardar el funciconamiento y composición de las Cámaras.

Finalmente, a la hora de valorar la legitimidad constitucional de ba limitación de un derecho serí imprescindible atender al peincipto de proporcionalidad o, to que es igual, a la existencia de una razonable relación de proporcionalidad entre los medios cmpleados y ta finalidad perseguida. Ya en su primera furispradencia ${ }^{\mathrm{N2}}$ el juez de la Conseitución razonaba que para determinar si las medidas limitadoras apljcudas eran necesarias para el fin persegudo, era preciso cxaminar si se habian ajustado al principio de proporciconalidad o bien si éste habia sido infringido.

Quiere todo ello decir que no basta sin mals la afinmacioin de un interés público para justificar el sacrificio de un derecho, pues, si asi fuera, la garantia consiluciona: perdera, relativiséndose, toda eficacia. En perfecta sintionía con esta urgumentacion el Trilbanal ha rectazado ${ }^{55}$ que casalquier fámula de motivación de un acuetdo denegatorio de un suplicario tenga per se b virtualidad de despejar cualquicr objeción a la constinucionalidad del acuerdo parla: mentarick "La fundamentación o motivación-2nade el Tribunal- en ciccto, no es ni puede ser garantía por si unisma, si no es en cuanto expresión de la coherencia del acuerdo parlamentario con la 'finall-

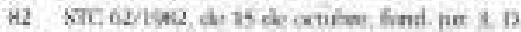
H3

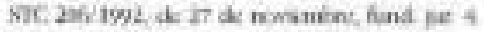

dad' de la inmunidad, a la vista de las exigencias del caso cancreto."

A la vista de todo lo expuesto, creemas que se puede comprender sin gran esfuer70 que el Tribunal Constitucional puede $y$ debe entrar a valorar si el juicio de oportunidad o de intencionalidad en que la Ca. mara ha basado la denegación del suplica. torio se ha ajustado a los criterios inmediatamente antes referidios, esto es; se ha motivado en términos razcnables, ha puesto de relieve la persecución de una finalidad constitucionalmente legttima, y se ha acomodado a las exigencias del principio de proporcionalidad.

A partir de las reflexiones precedentemente expuestas, puede comprenderse que pensenoos que el Tribunal Constitucional no ha dado un giro copernicano en su jurisprodencia cuando, como ba acomtecido en la sentencia 206/1992, ha entrado a revisar la suficiencia o insuficiencia de las razones contenidas en an acuerdo del Pleno del Senado denegatorio de la autorización para decretar el procesamienio del senador Ganzalez Bedoya ${ }^{\mathrm{B}}$.

In el citada fallo, el Trilxunal profundizando en la línea jurispeudencial avanzada en la sentencia 90/1985 $5^{\text {th }}$ - advierte que la expencia de un "jucicio do coparmunidad" sene zen sonrido pretominantemente matiorias; esto es, no se trata tanto de que el acuerdo adopte una "forma motivada", cuando de que exista en el -o quepa deducir del-acto parlamentaric una motiva-

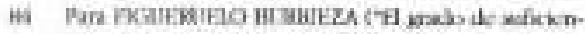

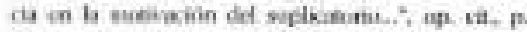

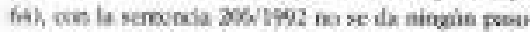

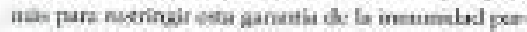

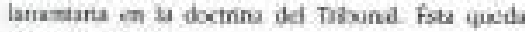
dreats ya ockitu.

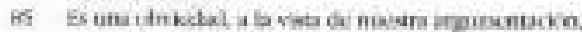

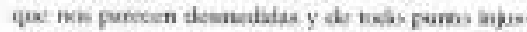

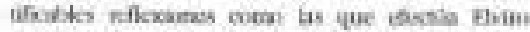

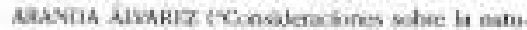

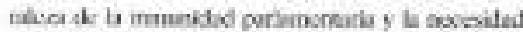


ción coherente con la finalidad cie la premogativa parlamentaria"15.

Y a partir de las cunsiderzciones precedentes no ofroce dudas al Tribunal la peocedencia de cotorgar el ampara solicitado, a la vista de la insuficiencia para fundamen tar una denegación, constitucionalmente legitima, de la autorización parn procesar al senador Gonzílez Bedoyat".

Entiende el Tribunal, con excelente criterio, en lines con su propia doctrina precedente, que "resulta claro que el instituto de la inmunidad no tiene como finalidad garancizar la libertad de expresion, ni aun cuando esta viene ejercida por un rejuresentante del pueblo espanolet. Por ocro lido, el hecho de que el sentor Ganzílez Bedoya actuara "en su calidad de senador" nos sitúa -siempre seguin el Tribunat- en un instituto procesalmente previo, cual es cl de la inviolabilictod parlamentaria, que, atendiendo a la doctrina constitucional, es paterise que no culse el supuesto de he-

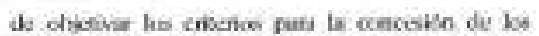

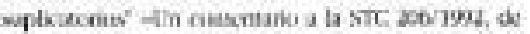

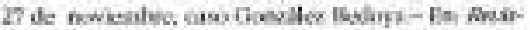

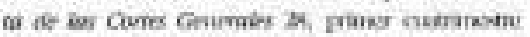

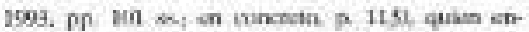

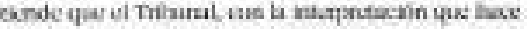

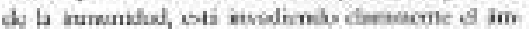

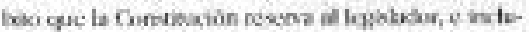

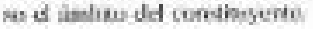

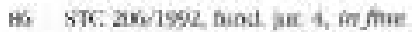

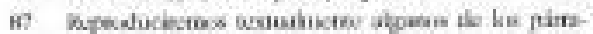

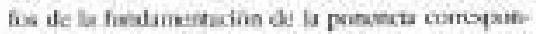

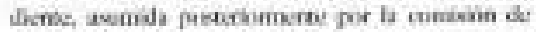

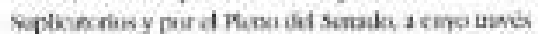

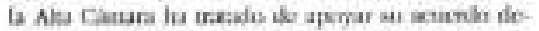
nowatcres

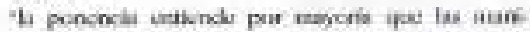

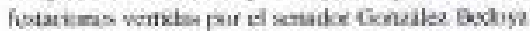

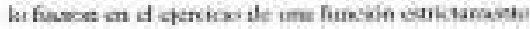

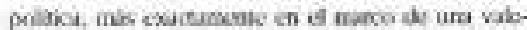

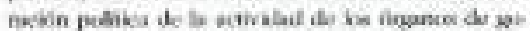

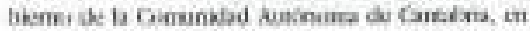

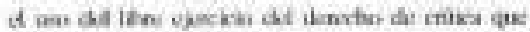

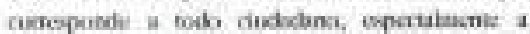

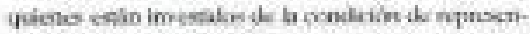

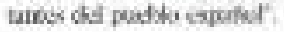

cho consermplado, pues, corno ya trivimos oportuniclad de ver, en lo sustancial la inviolabilidad sólo cubee la participación en actos porlamentarios.

Analizando el acuerdo del Senado en su conjunto, cree el juez de la Constitucicín que salta a la vista la omisión en el mismo de cualquier incidencia de la concesión o no del suplicatorio en la compasición de la Cimara o sobre su normal funcionamiento. No hay mada, en dicho acuerdo, que pueda considerarse relevante para el senticlo constitucionalanente perseggúlo a través de la prerrogativa de la inmunidad parlamentaria. Por lo mismo, el Alto Tribunal estima que el susodicho acuerdo del Pleno del Senaido ha vulnerado el derecho a la tutela fudicial efectivn de los jueces y tribunales al habet determinado, de forma contraria a derecho, el sobreseimiento de las querellas fombladas por los recurrentes, declaraindo, en consecuencia, la nulidad de aquel acuerdo def Senado.

La argumentación y decisión del Alto Tribural nos parece intachable. Bien es verdad que en dos de las tres votos particulares formulados frente a la sentencia no han escascado los juicios de notable dureza frente a la misma. $Y$ asi, en uno de ellos" se advierte que en el tallo que nos ocupa se da un salto cualitativo, de ral magritud, que contrasta llamativamente con la doctrina del Tribunal desarrollada a progxoito de la notivación de las semenclas y resoluciones de los úrganos judi-

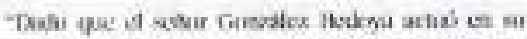

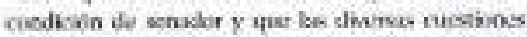

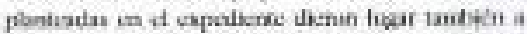

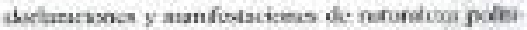

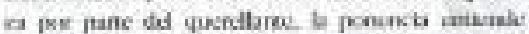

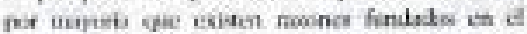

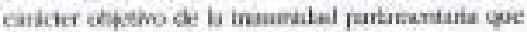

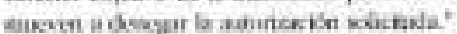

ss ste amase, hind ur s

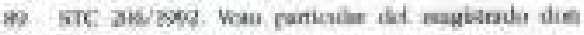
Atrmi thatrigase threip: 
cisles, y deja tan reducido el margen de apreciación politica a las Cámaras, que, salvo hipotesis patolópicas extremas de conflicto ente poderes difikilmente concebibles en un sistema democraltico, puede hacer prácticamente imposible la denegación de la previa autorización para inculpar o procesar a un diputado o senador $y$, con ello, hacer ilusoria la insritución de la inmunidad parlamentaria. $Y$ en otro de los $v_{0605^{90}} \mathrm{se}$ considera que ta revisión de la suficiencia o insuficiencia de las razones contenidas en el acuerdo de la Címana entraña un juicio de valor o una pontieración que, en principoxi, y salvo que se trate de una mera apariencia, equivale tealmente s ejercer la facultad de otorgar la inmuniclad.

Ya nos hernos manifestado con anterioridad respecto a L includibilidad de que el Tribunal controle no sollo el aspecto farmal de la existencia de motivación en el acuerdo parlamentario, sino que descienda al efectivo control material de be uisma, esto es, que a la vista de la motivación dada tesuelva acerca de si el acuerdo se acomoda a la finalidad constitucional a que responde el instituto de $\mathrm{la}$ inmunidad, finalidad que, no lo olvidemos, ha sido precisada por el Alto Tribumal, quien es el intẻrprete supremo de la Constitución.

Que al revisar la nocivacion politica del acuerdo el Tribunal venga a sustentar un juicio politico revestido de un lenguaje juridico 0 , si se prefiere, de un ropaje juridico, es una consideración que no hace sino remitirnos a una cuestión polénica pesmanentemente presente respecto de los mbunales constitucionales: la tensión cntre politica y derecho, que inquiere si loo gra ves problemas politicos que se sarecten a la dectaicen de un Tribunal Constinucionat pueden resolverse con las criteriod y los

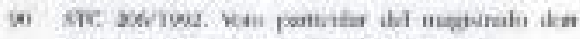

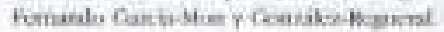

métodas de una decisión judicsal. En oltrimo término, la jurisdicuión constitucional óptuma no se zssenla en una consideración del ́́rgano titular de la misma como una instancia puramente técnica según los esquemas kelsenianos de la pureza metodi$\mathrm{Ca}_{3}$ apartándolo de la realidad vital del Estado, que es dinamismo politico; de ser así, el logro de a fieting Constizulion, una Constitución viva, vigeme, acorde con la realidad social, seria mera utopia.

Por lo demís, los problemas que suscita la inmunidad, los aspectos contradicto. rios de la misna, hacen harto difieil -camo admxe Pizzorusso" - reconducirla a exquemas colkerentes y racionales, resultando a menudo todavis más desconcertante el examen de la praxis. $Y$ es que no creencos que vaya muy descaminada la amplia doctrina que en los últimos tiempos ha criticado con dureza la garantia de la inamunidid calificandola de una institución anacrónica, obsioleta y contraria a las principlos fundamentales det arodemo derecho constitucional ${ }^{\mathrm{q} 2}$.

Por todo ello, en el marco de un Estado que asegura el imperio de la ley coavo ex. presicon de la voluntad popular, una institución como la de la inmunidad está llama. da a ser poco opecativa, Quizá -como dice Femández Viagas ${ }^{2+}$ las Carmaras, al decidir sobte la concestión o no de un supliciltorio, sólo dełerian tener en cuenta las repercusiones que la acción pucliera com portar sobere su crumposición política. Esto es, se tratarta de deverminar si la presencia

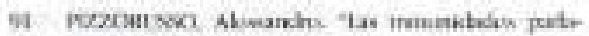

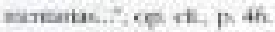

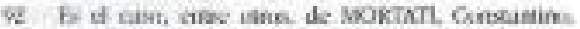

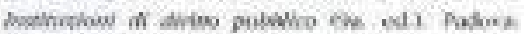

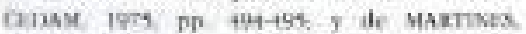

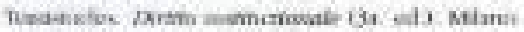
Geifhe t5st of 913

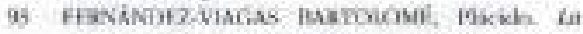

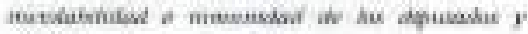

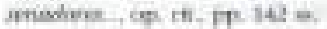


de un parlamentario es imprescindible para mantener la composición ideológica de la Asambiea, resultandole indispensable matenerie en la Cimara, en crden al respeto de las reglas del juego denocratico. $Y$ cuanto propicie una interpretación expansiva $y$ al margen de su finalidad constifucional -determinada port el intérprete supremo de la Constitución", can el subsiguiente impacto sobre la vigencia de derechas fundamentales de tercerce-, es evidente, a nuestro parecer, que debe ser rechazado $y$, en el oportuno control en sede constitucional, declarada nulo por ilicitud constitucional. Se nos podrí decir que el margen de vigencia de cste instituto de naturaleza procesal estí llamado a ser mínimo si así se cancibe, pero ello no es raxón suficiente comb para desechar esta concepción restrictiva que, por lo demás, no conduce a vaciar radjcalmente de contentdo a esta inseitución constitucional.

\section{EL PRIVILEGIO DE FUERO}

El articulo 71.3 de nuestra Lex superior establece el que se concoce como prittiegio de fuero o fworo prifilegrado, que, aun cuando con mucha menor trascendencia que la inviolabilidad y la inmunidad, se ubica junto a ellas entre las prerrogativas partamentarias.

El privilegio consiste, como resulta obvio, en la residencia, en el Tribunal Supremo, de la competencia para juzgar las causas abiertas contra los parlamentarios. En el pussudo esta garantía, en algunos países, se conformó camo el derecho de ciertos parlamentarios a ser juzgados por la propia Asanblea a la que pertenecian. Asi, en Inglaterra, hasta su abolición por la Orminal justice Act de 1948, los Inces gozaron de] privilegio de set jazgados por sus propios pares.
Como bien sethala Pizzorusso", alli donde una atribución de competencia de este género se realiza mediante una ley pervia a los hechos sabre tos que se ha de juzgar, no puede encontrarse violación alguna del paincipio del juez natural, que requiere la predeterminación del juez, pero que no excluye on absoluto que las normas sobre la jurisdicción y sobre la comperencla puedan prever excepciones a las reglas generales que ellas mismas adoptan.

En nuestro pais, el hecho de que el pronunclamiento judicial sez en una sola instancia darla ple a un recurso de amparo ante el Tribunal Constitucional, asentado en la consideración de que el cardeter firthe y definitivo de la sentencia de la Sala de lo Peral del Tribunal Supremo volneraba el artículo 24 de la CE, que, interpretado de conformidad con el articulo 16 del Pacto Internacional de Derechos Civiles y Politicns, ratificado por Espana, debe reconocer la garantia al doble grado de jurisdicción en materia penal.

El Alto Tribunal rechazaráa el amparo solicitado al entender, siguiendo una muy reiterada doctrisa, que el articulo 14 del citado pacto internacional, aunque es derecho intemo, no es bastante para crear per se recursos inexistentes en nuestro orderamiento ${ }^{\text {s. }}$.

En otro monento" el juez de la Consttucion ha sefnalado que el hecho de que determinachas personas gocen, ex Consfitutione, y en atención a su cargo, de una especial protección, contrarresta la imposibilidad de scudir a una instancia superior, pudiendo afirmarse que "esas particulares

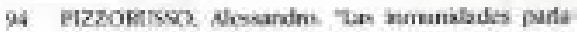
unenorus:; op a

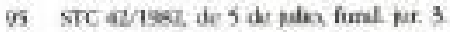

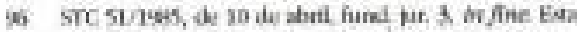

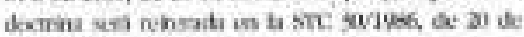
fetrese find pr. 2 
ganntias que acompantan a diputados y senadores disculpan la falta de un segundo grado jurisdiccional, poc ellas mismas $y$ parque el óryano encargada de conocer en las causas en que puedan hallarse inplicadas es el superior en la vía jurisdiccional coclinaria". 